\title{
REGIONAL INNERVATION OF RABBIT CILIARY GANGLION CELLS BY THE TERMINALS OF PREGANGLIONIC AXONS ${ }^{1}$
}

\author{
CYNTHIA J. FOREHAND AND DALE PURVES
}

Department of Physiology and Biophysics, Washington University School of Medicine, St. Louis, Missouri 63110

Received April 25, 1983; Revised June 20, 1983; Accepted June 27, 1983

\begin{abstract}
In the rabbit, ciliary ganglion neurons with dendrites maintain inputs from several different axons during the period of synaptic rearrangement that occurs in early postnatal life. Neurons without dendrites, on the other hand, lose the majority of their initial inputs and are innervated in maturity by the terminals of only one or two axons (Purves, D., and R. I. Hume (1981) J. Neurosci. 1: 441-452; Hume, R. I., and D. Purves (1981) Nature 293: 469-471). We have explored the basis of this phenomenon by individually marking preganglionic axons and the neurons they innervate with horseradish peroxidase. In general, the innervation of geometrically complex (multiply innervated) neurons by individual preganglionic axons is regional. That is, the synaptic contacts made by an axon on these neurons are limited to a portion of the postsynaptic surface that includes some, but not all, of the dendrites. This regional innervation of target neurons is consistent with the view that dendrites allow multiple innervation to persist by providing relatively separate postsynaptic dom ins for individual preganglionic axons. Such regional innervation may mitigate competitive interactions between the several axons which initially innervate the same neuron.
\end{abstract}

During development, neurons become innervated by a characteristic number of axons. In the mammalian nervous system the number of inputs to individual target cells varies from one to at least tens of thousands (see, for example, Fox and Barnard, 1957; Lichtman, 1977). The way in which the degree of innervation is regulated is important both for neuronal integration and for the establishment of specific patterns of synaptic connections. Two recent findings in the autonomic nervous system of mammals may help explain the way in which axonal convergence onto target neurons is determined. First, many neurons in autonomic ganglia are innervated by more axons at birth than in maturity (Lichtman, 1977; Lichtman and Purves, 1980; Johnson and Purves, 1981): the axons which initially innervate the same neuron apparently compete with one another during a relatively prolonged period in which the final number of inputs is established (see Purves and Lichtman, 1980). Second, the outcome of this process is closely tied to the geometry of individual postsynaptic neurons: cells in the rabbit ciliary ganglion which lack dendritic processes

\footnotetext{
${ }^{1}$ We are grateful to R. I. Hume, J. W. Lichtman, E. Rubin, and J. R. Sanes for useful discussions and criticism, to E. Gordon for her unfailing help, and to V. Friedman for assistance with the illustrations. This work was supported by National Institutes of Health Grants NS11699 and NS-18628 and by the Muscular Dystrophy Association. C. J. F. was supported by Training Grant T32NS-07071-40.
}

receive several (four to six) inputs at birth but are innervated in maturity by boutons that arise from only one or two preganglionic axons, whereas neurons with dendritic processes generally maintain innervation by a number of different preganglionic axons that increases in proportion to the complexity of their dendritic arbors (Purves and Hume, 1981; Hume and Purves, 1981). A similar relationship between the number of inputs and postsynaptic geometry appears to hold for sympathetic neurons in maturity (D. Purves and J. W. Lichtman, unpublished observation). The implication of these findings is that postsynaptic geometry influences the normal elimination of some synaptic connections.

By intracellular stimulation and subsequent horseradish peroxidase (HRP) staining of individual preganglionic axons, Hume and Purves (1983) found that each preganglionic axon in the rabbit ciliary ganglion innervates a relatively small number of target neurons (about 10 to 20) which are scattered throughout the ganglion. Moreover, they found relatively little mixing of labeled and unlabeled boutons on postsynaptic profiles examined in the electron microscope. On the basis of these observations, it was suggested that sets of terminals from different axons innervating the same ganglion cell might be separated from one another.

In the present work we have explored this possibility by examining the apportionment of innervation from single axons to individual rabbit ciliary ganglion cells 
and their dendrites after injecting both the pre- and postsynaptic elements with HRP. Our results show that individual axons often innervate a restricted portion of the postsynaptic cell. In particular, ganglion cells with several dendrites usually receive innervation from a given axon on only some of their processes. Furthermore, individual axons often show a striking affinity for particular dendrites, following them closely for long distances while ignoring the surfaces of adjacent postsynaptic cells. These findings are consistent with the idea tht multiple innervation persists on geometrically complex postsynaptic neurons because the sets of terminals from different axons are segregated to some degree.

\section{Materials and Methods}

Adult rabbits were anesthetized with pentobarbital and both ciliary ganglia were removed. Isolated ganglia were placed in a Lucite chamber and superfused with an oxygenated saline solution at room temperature; the preand postganglionic nerves were drawn into suction electrodes for stimulation and recording, respectively (see Johnson and Purves, 1981, for details). Ganglion cells and preganglionic axons were impaled with microelectrodes which were pulled from triangular glass (Glass Co. of America) and filled with 5\% HRP (Sigma, type VI) in $0.2 \mathrm{M}$ potassium acetate buffered to $\mathrm{pH}$ 7.6. Ganglion cells were identified by the presence of synaptic potentials and large, overshooting action potentials in response to preganglionic stimulation (Fig. $1 A$ ); preganglionic axons were identified by the presence of smaller, fast-rising action potentials which lacked a synaptic component (Fig. 1B; see also Hume and Purves, 1983). In each ganglion, HRP was injected into 15 to 50 ganglion cells for 30 to $60 \mathrm{sec}$ with 50 -msec depolarizing pulses of $5 \mathrm{nA}$ at $5 \mathrm{~Hz}$; $\mathrm{HRP}$ was also injected into 5 to 15 preganglionic axons for 3 to $10 \mathrm{~min}$ using the same parameters. The injection times were chosen to give lightly stained ganglion cells and heavily stained preganglionic axons. With these injection times about $40 \%$ of the impaled ganglion cells were successfully stained. Of the 5 to 15 axons injected in each ganglion, however, only one or two were successfully marked. Presumably, the low percentage of successfully stained axons was due to the small diameter of the preganglionic fibers (on the order of $1 \mu \mathrm{m}$ ). There are about 400 ganglion cells and 40 ipsilateral preganglionic neurons in this system; taking into account the number of inputs ganglion cells receive, the average preganglionic neuron innervates about 10 to 20 target cells (Johnson and Purves, 1981; Hume and Purves, 1983). Therefore, labeling one or two dozen ganglion cells and one or two preganglionic axons gave us a reasonable chance of finding synaptic connections between labeled pre- and postsynaptic neurons in any given ganglion.

Ganglia were fixed overnight in $1.25 \%$ glutaraldehyde and $0.5 \%$ paraformaldehyde in HEPES buffer at $\mathrm{pH}$ 7.6. They were then rinsed in HEPES buffer and equilibrated in phosphate-buffered $30 \%$ sucrose. Fifty-micrometer frozen sections were cut on a sliding microtome, and the HRP reaction product was developed by the method of Hanker et al. (1977). Sections were mounted serially onto slides for examination in the light microscope at $\times 1200$.
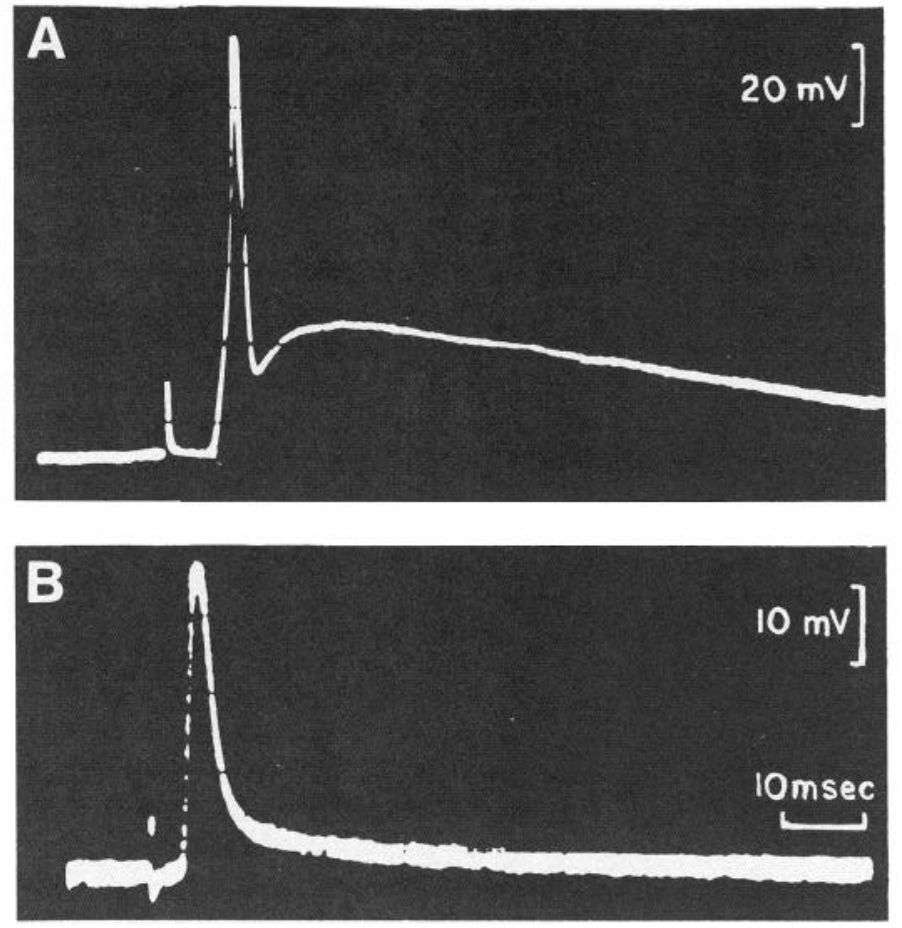

Figure 1. Intracellular records from a ciliary ganglion cell and a preganglionic axon. Microelectrodes were advanced through the ciliary ganglion while stimulating the preganglionic (oculomotor) nerve with brief current pulses. Impalements of ganglion cells $(A)$ were characterized by overshooting action potentials that arose from synaptic potentials and were followed by continuing synaptic depolarization. Action potentials recorded from preganglionic axons $(B)$ were much smaller, arose with a shorter latency, and had no synaptic component. Note the different gain in $A$ and $B$.

Although this small ganglion was usually traversed in three or four sections, the large number of labeled profiles in each ganglion made it difficult to reconstruct particular cells from one section to another. In the results that follow, therefore, we usually refer to neuronal processes rather than specifically identifying axons and dendrites of postganglionic cells. Moreover, since some processes orthogonal to the plane of section may not have been observed, the number of neuronal processes that we counted represents a minimum. Finally, the criterion for scoring a preganglionic axon as associated with a process of a labeled ganglion cell was that the axon follow the process for at least a cell body diameter and make one or more synaptic boutons on it. Thus we did not score an association consisting of one or a few boutons at the base of a dendrite which was otherwise free of contacts (see Fig. 2 for example).

\section{Results}

\section{Contacts between pairs of HRP-labeled pre-and postsynaptic elements}

In the course of this study we injected HRP into 2574 ganglion cells and 825 preganglionic axons in 101 ciliary ganglia. In this sample we found 30 unambiguous instances where a labeled preganglionic axon invested a labeled postsynaptic ganglion cell with preterminal pro- 

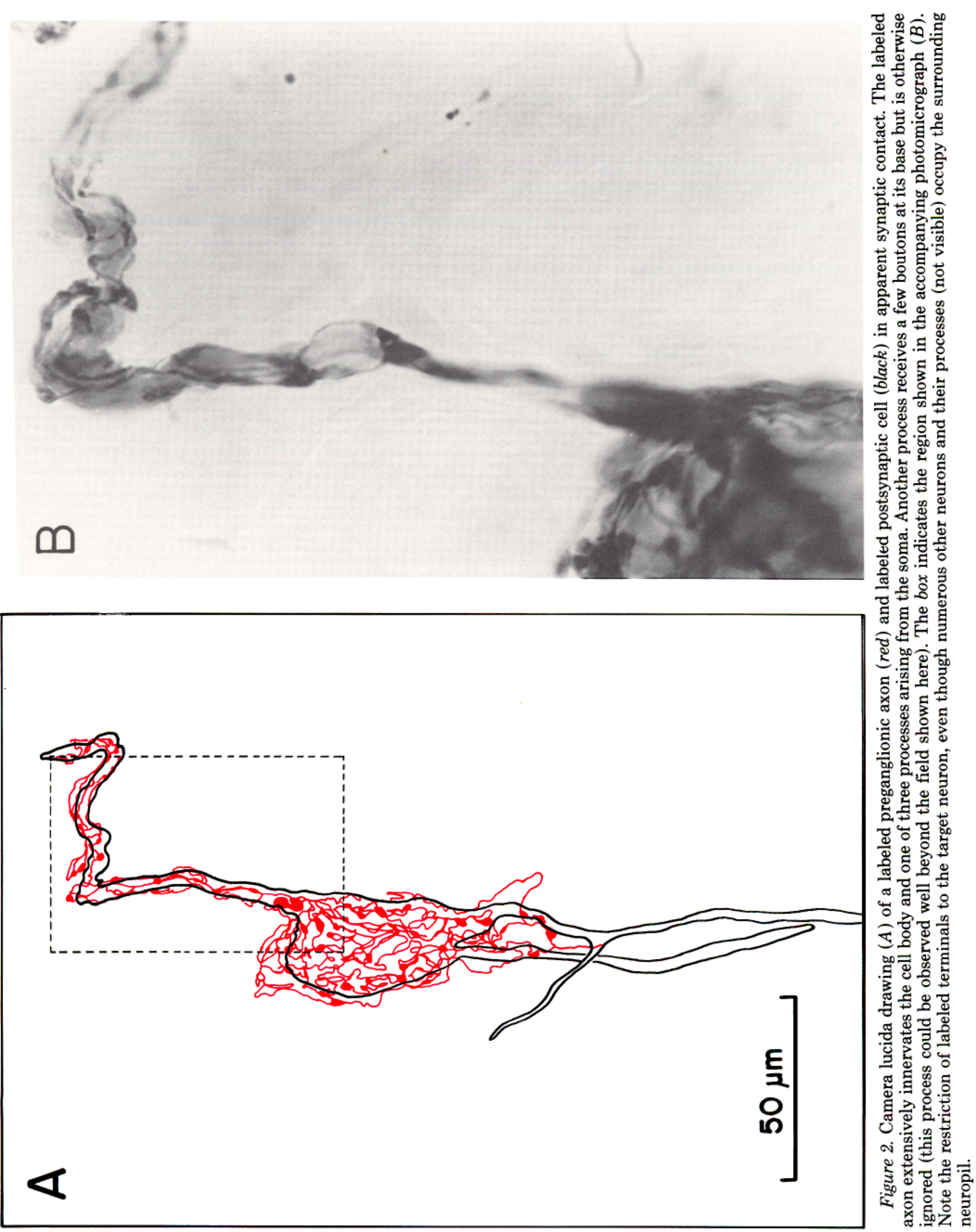


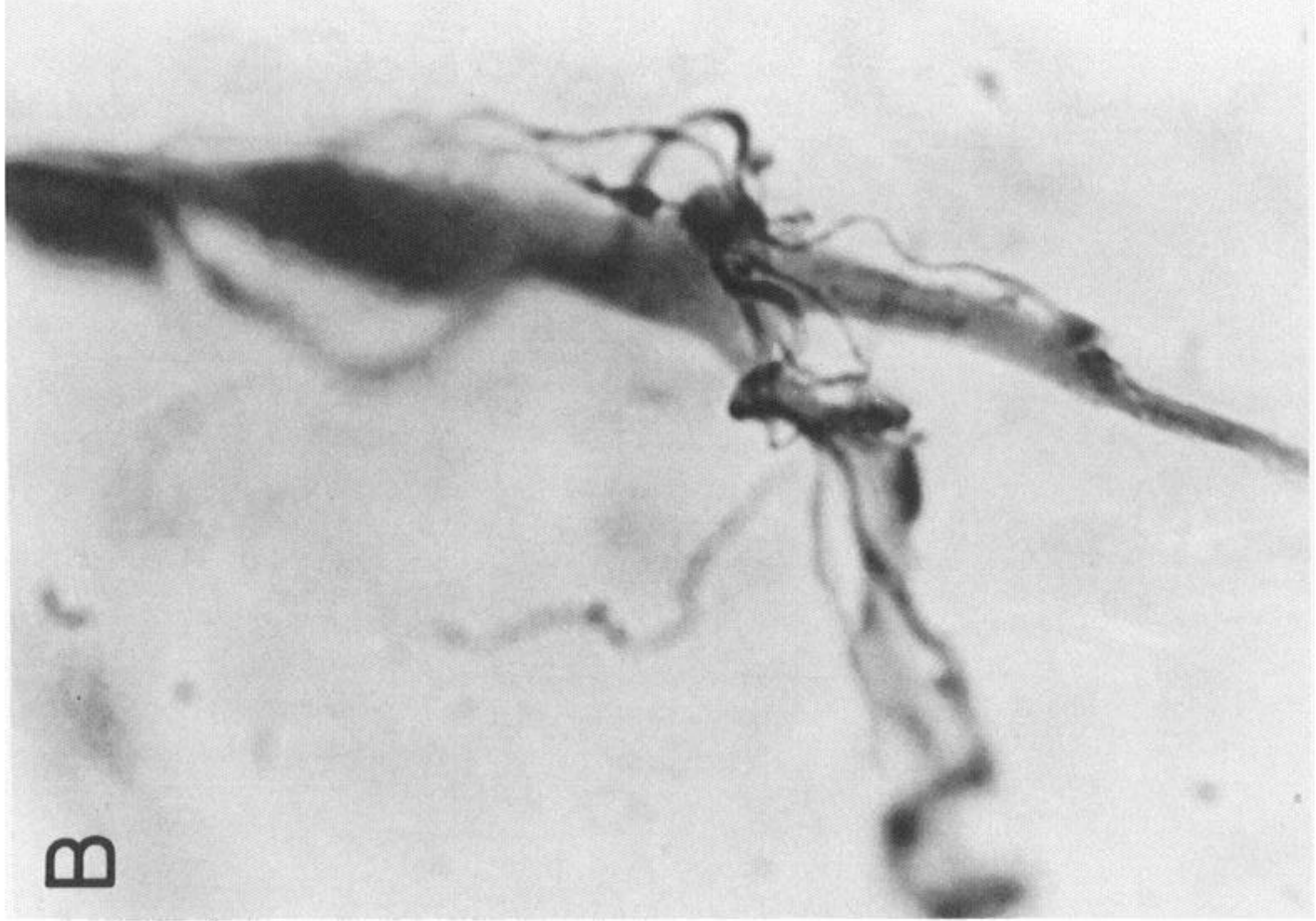

꼻

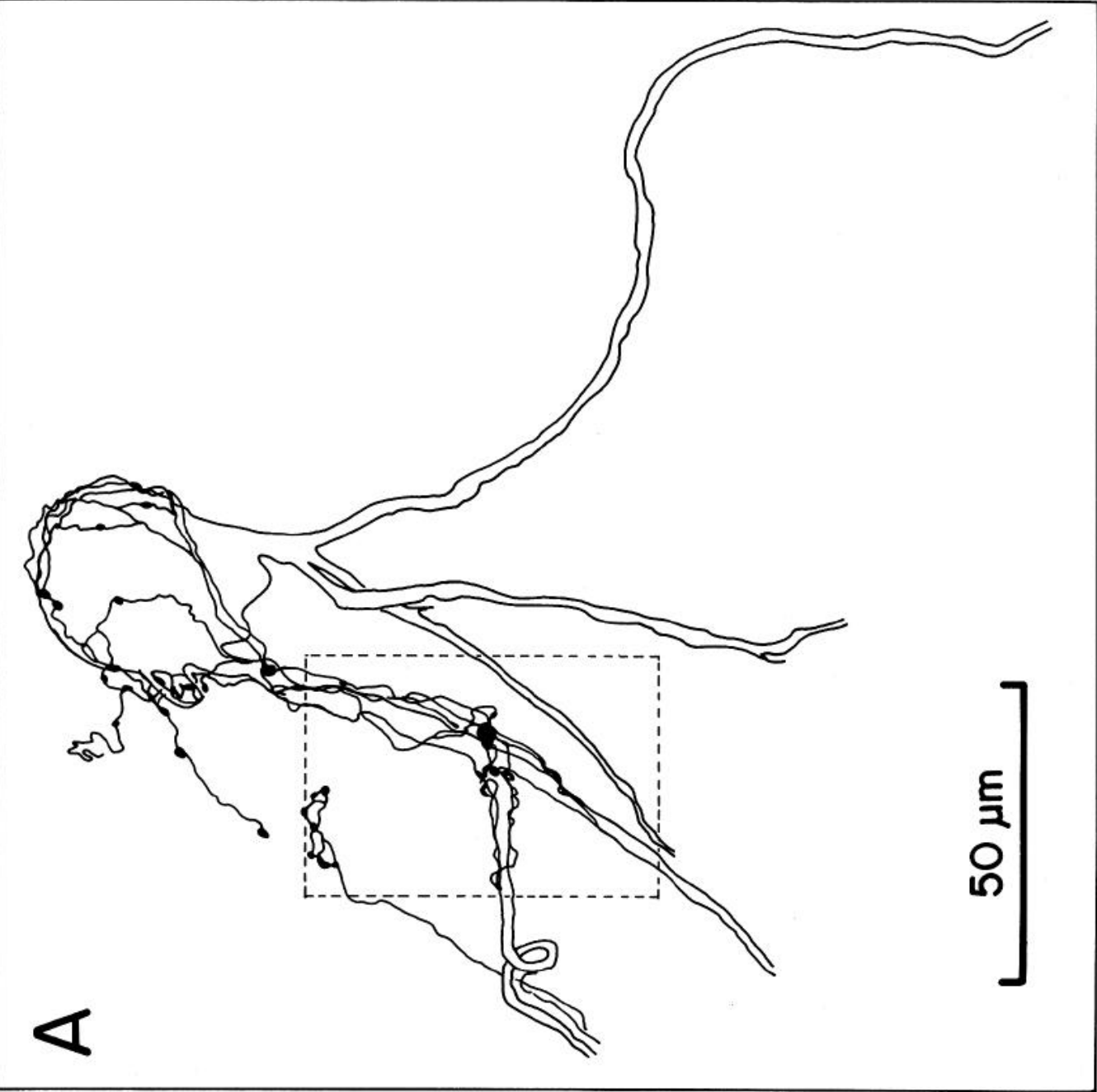

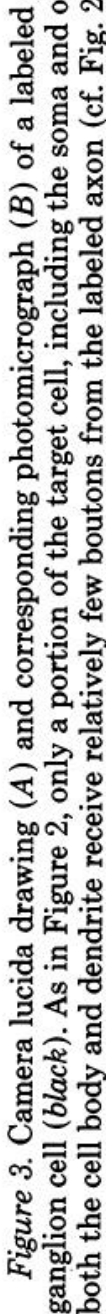


cesses and boutons. In each of these cases the labeled axon terminals appeared to follow the contour of the labeled postsynaptic cell while ignoring other nearby neurons (Figs. 2 and 3 ). This restriction of a preganglionic axon to a particular target cell within a given area of neuropil was characteristic of the innervation of both the dendrites and the somata of target neurons.

Although the density of labeled boutons on different target neurons was variable (see below), when the labeled axon made synaptic boutons on a labeled dendrite some boutons were nearly always present on the cell soma (13 of 16 cases; see Table I). We did, however, observe three cases in which axon terminals seemed to be associated with a dendrite but not with the relevant cell body. The significance of the apparently low incidence of the innervation of dendrites alone is hard to address because considerable bias may have been introduced by the difficulty of seeing a few synaptic contacts on dendrites. Nonetheless, our impression was that substantial innervation of a ganglion cell dendrite was usually associated with at least some innervation of the related cell body.

Labeled preganglionic terminals were not distributed over the full extent of individual postsynaptic cells. In 16 of the 24 cases in which the labeled postsynaptic neuron had more than one process, the terminals of the labeled axon followed only some of the processes that arose from the postsynaptic cell body (Table I; see also Figs. 2 and 3). In the remaining eight cases, the labeled presynaptic boutons were limited to the cell body, even though the target cell had two or more processes arising from it. When the labeled postsynaptic cell gave rise to only a single process (presumably the postganglionic axon), the labeled preganglionic axon did not extend along the process (four cases; see Table I). Nor did the labeled preganglionic axon follow the postganglionic axon in instances where the axon of a labeled ganglion cell could be identified within the section by virtue of extension into a postganglionic nerve. Finally, two labeled ganglion cell somata contacted by a labeled axon had no processes evident within the section.

Taken together, these observations provide strong evidence for the regional innervation of target cells by individual preganglionic axons. Evidently, a common relationship between an axon and a ganglion cell is the extension of a preganglionic axon along one of several major dendritic processes accompanied by a variable degree of cell body innervation.

\section{Additional observations on the distribution of labeled preganglionic axons}

In order to extend these observations made on a limited number of labeled pairs, we took advantage of the fact that labeled preganglionic axons often traced the outlines of unlabeled target cells. By analyzing these outlines we could assess the results from labeled pairs within a larger population of target cells.

Innervation of ganglion cell bodies. Nests of preganglionic terminal boutons often outlined what appeared to be ganglion cell bodies (see Figs. 2 and 3). That such nests represent the innervation of ganglion cell somata has been confirmed in the electron microscope (Hume and Purves, 1983). The number of synaptic boutons made by individual axons on presumptive ganglion cell bodies varied over at least an order of magnitude (range, 3 to 94 boutons; mean $=28.5$ boutons, $n=336$ ). These results are in accord with the number of cell body boutons counted on labeled cell pairs (cf. Figs. 2 and 3) and with an earlier study in which ganglia were examined in whole mounts after preganglionic axon injection (Hume and Purves, 1983).

The approach of a labeled axon to an invested cell body was often by means of a single process which traversed relatively long distances without elaborating synaptic boutons (see Figs. 4, 5, and 7). Occasionally a preganglionic axon spiraled near the cell body (Fig. $4 \mathrm{~A}$ ) in a manner reminiscent of the innervation of target cells in frog autonomic ganglia (see, for example, McMahan and Kuffler, 1971). Much more often, however, the preterminal axon was distinguished only by the absence of boutons. In many cases the same axon could be traced in continuity to more than one cell body. In these instances it was apparent that the same axon could heavily invest some cell somata while innervating others only lightly (Fig. 4B; see also Fig. 7). This observation suggests that the number of boutons made by an axon on a

TABLE I

Regional innervation of HRP-labeled postsynaptic neurons by individual HRP-labeled preganglionic axons ${ }^{a}$

\begin{tabular}{|c|c|c|c|}
\hline Example & $\begin{array}{l}\text { No. of Processes } \\
\text { Extending from the } \\
\text { Labeled Ganglion Cell }\end{array}$ & $\begin{array}{l}\text { No. of Postsynaptic } \\
\text { Processes Contacted } \\
\text { by Labeled Axon }\end{array}$ & $\begin{array}{c}\text { Cell Body } \\
\text { Contacted by } \\
\text { Labeled Axon }\end{array}$ \\
\hline 1 & 1 & 0 & Yes \\
\hline 2 & 1 & 0 & Yes \\
\hline 3 & 1 & 0 & Yes \\
\hline 4 & 1 & 0 & Yes \\
\hline 5 & 2 & 1 & Yes \\
\hline 6 & 2 & 0 & Yes \\
\hline 7 & 2 & 1 & Yes \\
\hline 8 & 2 & 1 & Yes \\
\hline 9 & 2 & 0 & Yes \\
\hline 10 & 2 & 1 & Yes \\
\hline 11 & 2 & 1 & Yes \\
\hline 12 & 2 & 0 & Yes \\
\hline 13 & 2 & 0 & Yes \\
\hline 14 & 2 & 1 & No \\
\hline 15 & 2 & 1 & No \\
\hline 16 & 3 & 0 & Yes \\
\hline 17 & 3 & 1 & Yes \\
\hline 18 & 3 & 2 & Yes \\
\hline 19 & 3 & 1 & Yes \\
\hline 20 & 3 & 1 & Yes \\
\hline 21 & 3 & 0 & Yes \\
\hline 22 & 3 & 1 & Yes \\
\hline 23 & 3 & 0 & Yes \\
\hline 24 & 3 & 2 & No \\
\hline 25 & 4 & 1 & Yes \\
\hline 26 & 4 & 2 & Yes \\
\hline 27 & 4 & 1 & Yes \\
\hline 28 & 4 & 0 & Yes \\
\hline
\end{tabular}

${ }^{a}$ Two cells which received somatic innervation but had no processes are not included. 


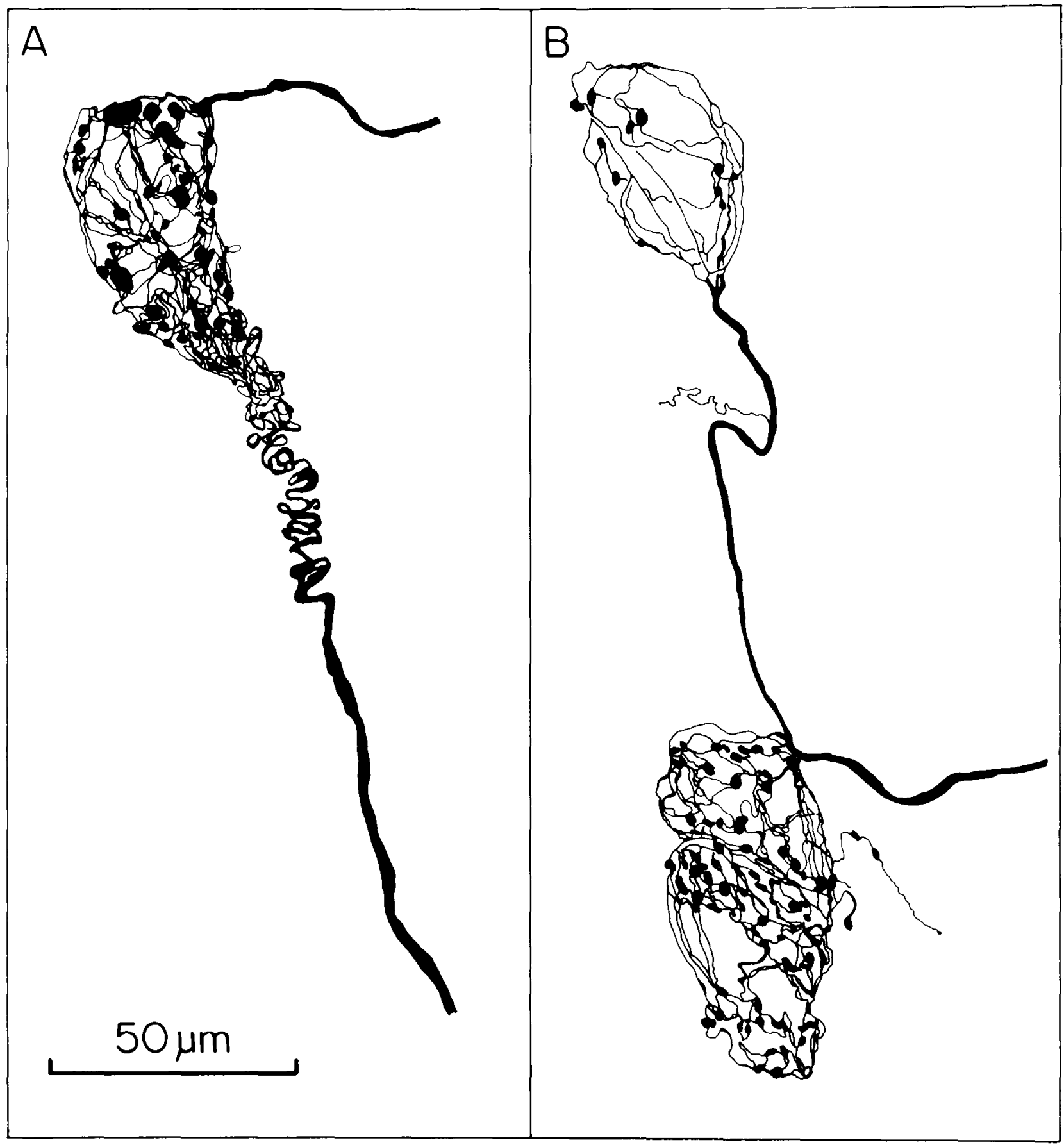

Figure 4. Camera lucida drawings of the investment of presumptive (unlabeled) ganglion cell bodies by HRP-labeled axons. $A$, Example of a target cell body heavily invested by preterminals and synaptic boutons. Note the spiral of the preganglionic axon near the target cell body. $B$, The upper ganglion cell body is only lightly invested by the terminals of a labeled axon, whereas the same axon heavily invests two nearby target cells (bottom). 
target cell is not an intrinsic property of the axon but rather is the result of interactions at the level of the target cells.

Innervation of ganglion cell dendrites. In addition to outlining ganglion cell somata, labeled preganglionic processes bearing synaptic boutons frequently extended away from invested cell bodies in a manner similar to that shown in Figures 2 and 3. Although the complexity of labeled processes that occurred when several target cells were innervated contiguously sometimes obscured the arrangement of boutons in the vicinity of an innervated cell body, the details of these extensions could often be studied. Such extensions frequently appeared to outline a process arising from an invested cell body (Fig. 5). Indeed, several terminal branches from a labeled axon commonly ran together over a long course as if closely applied to a particular dendritic process, in much the way that labeled axons followed a particular process of a labeled postsynaptic cell (cf. Figs. 2 and 3).

These extensions of labeled terminals away from innervated somata bore a variable number of boutons along the course of what we presumed to be neuronal dendrites (Fig. 5; see also Figs. 2 and 3). Although there was no : imple way to compare the density of cell body and iendritic innervation, the variation of labeled bouton density on different putative dendrites appeared to be similar to the variation of cell body innervation described in the preceding section.

Whether these particular outlines represent postsynaptic cells with more than one process is, of course, not known; however, labeled preganglionic elements that extended away from a given cell body did not match the dendritic complexity of injected ganglion cells observed in $50-\mu \mathrm{m}$ sections. Thus the average number of processes radiating from labeled ganglion cells was much greater than the number of labeled preganglionic extensions away from invested cell somata (Fig. 6). The discrepancy between the number of dendrites arising from the somata of labeled ganglion cells and the smaller number of labeled extensions away from presumptive cell bodies invested with labeled preganglionic terminals is in accord with the results from our analysis of labeled cell pairs. Both sets of observations indicate that the terminals of a particular axon innervate only some of the dendrites arising from a ganglion cell.

The distribution of target cells innervated by a labeled preganglionic axon within the ciliary ganglion. Individual preganglionic axons innervated target neurons that were widely scattered in the ganglion (Fig. 7). Although the majority of ganglion cell somata outlined by the terminals of a single labeled preganglionic axon occurred in isolation, there was an obvious tendency for an axon to innervate several contiguous target cells in clusters of up to five neurons (Figs. 7 and 8). The occurrence of such clusters indicates that the distribution of the target cells innervated by an axon is not completely random, and suggests that the innervation of one target cell increases the probability of innervation of adjacent neurons by that axon. Within such groups, each target neuron appeared to be innervated in the same manner as neurons in isolation (see Fig. 7): in both cases individual target. cells were strongly preferred to the majority of nearby neurons.

\section{Discussion}

The degree of axonal convergence onto individual neurons in the rabbit ciliary ganglion is closely lied to the geometry of the target cells; thus ganglion cells that lack dendrites are innervated by a single axon, whereas neurons with dendrites are innervated by a number of different axons that increases in proportion to the complexity of their dendritic arborizations (Purves and Hume, 1981; Hume and Purves, 1981). The present results analyze the distribution of the terminals of single axons on individual ganglion cells and give some insight into a likely basis for this correlation.

\section{Evidence for regional innervation of postsynaptic cells by preganglionic axons}

Broadly speaking, the postsynaptic neurons in this ganglion are functionally homogeneous (Johnson and Purves, 1983). In spite of this homogeneity, the boutons arising from an axon are restricted to only a few target cells, whereas most other neurons in close proximity receive no innervation from that axon (see also Lichtman, 1980). Whatever the mechanism that promotes the elaboration of many boutons from a given axon on a few postsynaptic cells, the present results show that this feature of ganglion cell innervation applies to the dendrites of individual cells as well as being characteristic of cell body innervation. Moreover, an axon that innervates a multiply innervated target cell tends to confine itself to only a part of the postsynaptic cell, ignoring some of its dendritic processes (and probably its axon).

This regional innervation of ganglion cells by preganglionic axons appears to be fundamentally different from regional innervation by different classes of inputs to some central neurons. Pyramidal cells in the hippocampus, for example, receive different classes of inputs on different parts of the neuron (Hamlyn, 1963; Blackstad, 1967); in this case, regional innervation is presumably based on the laminar organization of the hippocampus and/or a chemical mosaicism of the postsynaptic cell. In the present case, a single class of input is apportioned according to competitive interactions between the innervating axons.

Apportionment of innervation to ganglion cell dendrites. The results obtained both from analysis of labeled pairs and from the configurations of preganglionic terminals imply that the sets of terminals contributed to a target cell by different axons are to some degree separated from one another on a ganglion cell with dendrites. This conclusion is also supported by the finding that, in electron microscopic sections, dendritic profiles of mature ciliary ganglion cells which received contacts from a labeled preganglionic axon tended to receive most other terminals in that region from the same axon (Hume and Purves, 1983). Since ciliary ganglion cells which have dendrites are usually multiply innervated (Purves and Hume, 1981), it seems probable that the dendrites ignored by one axon are innervated by the terminals of a different axon. 

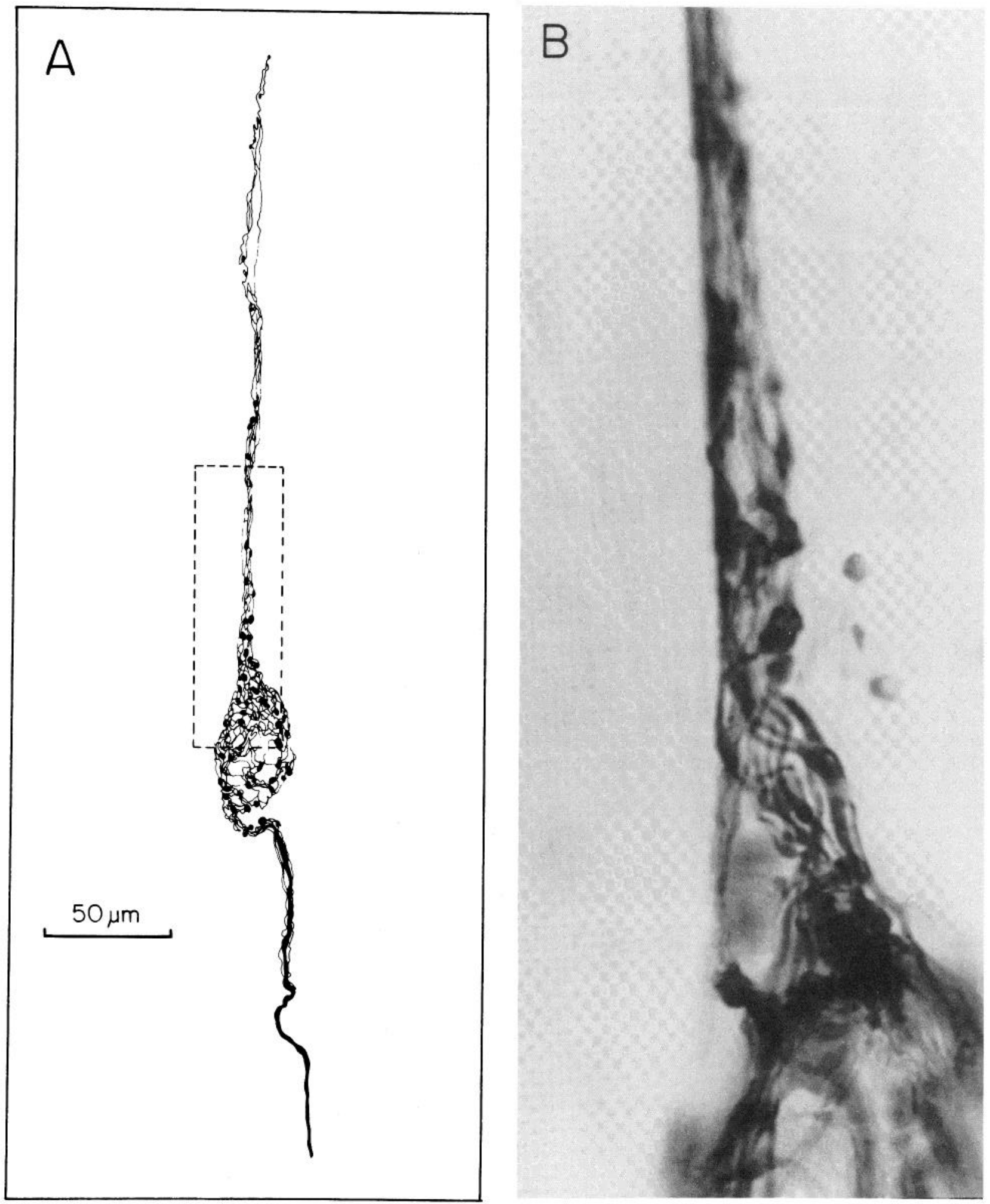

Figure 5. Extensions of labeled axons away from invested target cell bodies. $A$, Camera lucida drawing of an axon apparently investing a cell body and extending along a process of the invested neuron. $B$, Photomicrograph of the box in $A$. Note the sharp restriction of the labeled innervation within the neuropil. $C$ to $E$, Camera lucida drawings of additional preganglionic axons which appear to extend along a process arising from an invested ganglion cell body (cf. Figs. 2 and 3 ). 


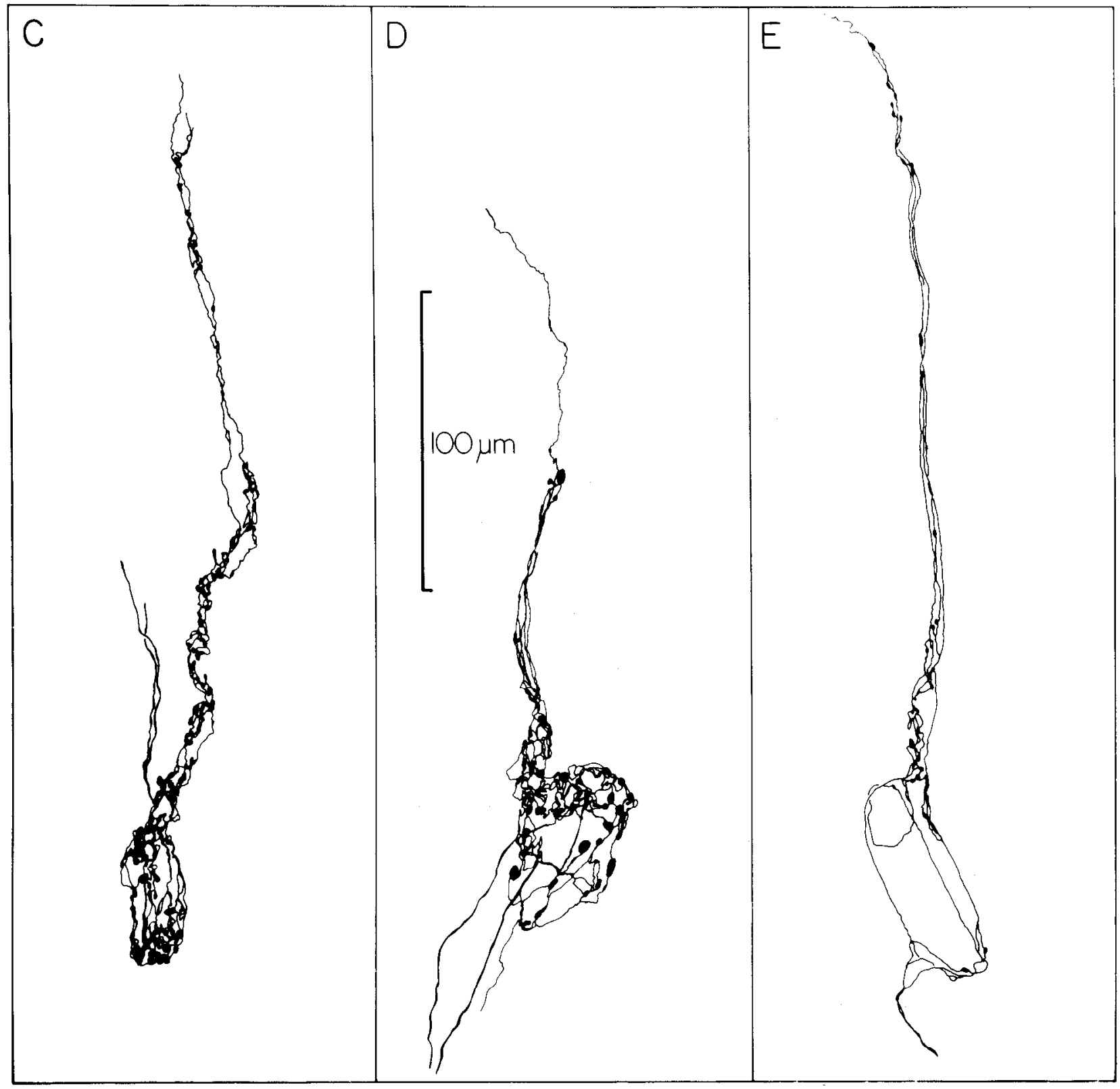

Figure 5, C-E 


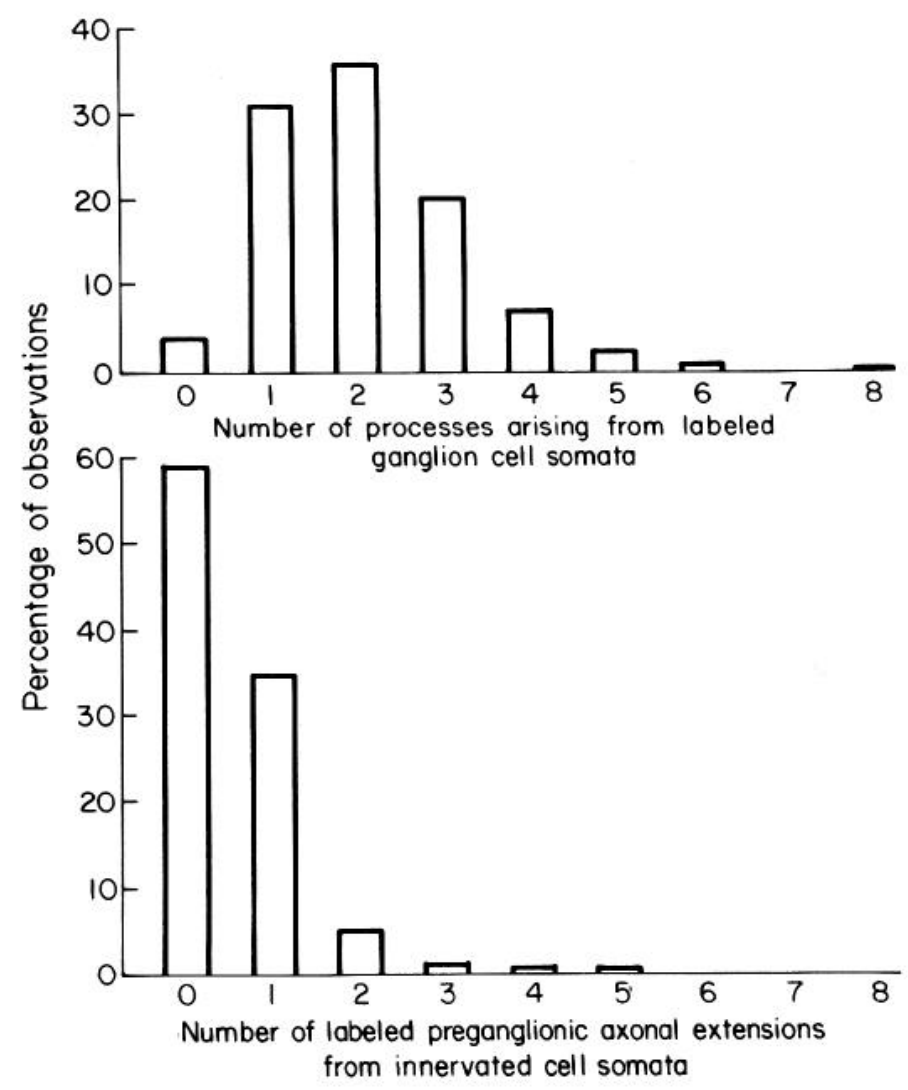

The segregation of inputs from individual axons onto different dendrites is probably incomplete since, at the electron microscopic level, both HRP-labeled and unlabeled preganglionic terminals were sometimes found on the same postsynaptic profiles (Hume and Purves, 1983). In accord with this, it seems likely that the relatively light innervation of some dendrites implied by fine axon terminals with only one or a few boutons along their length (see, for example, Figs. 3, $5 E$, and 7) represents a minor contribution to a dendrite whose innervation is dominated by one or more additional axons.

The innervation of ganglion cell somata. The apportionment of innervation from different axons to ganglion cell somata may be more complex. Although Hume and Purves (1983) found some mixing of labeled and unlabeled terminals on ganglion cell somata, many cell bodies were exclusively captured by the terminals of one axon.

Figure 6. Comparison of the numbers of processes arising from HRP-labeled ganglion cells in $50-\mu \mathrm{m}$ sections $(A)$ and the number of labeled preganglionic extensions associated with presumptive ganglion cell somata $(B)$. The marked difference between the two histograms is consistent with other evidence indicating that individual preganglionic axons follow only some of each target cell's processes. The sample in $B$ includes only those cells in which the number of extensions could be judged accurately; cases where a complex cluster obscured this aspect of innervation were omitted ( $n=1033$ in $A ; 365$ in $B)$.

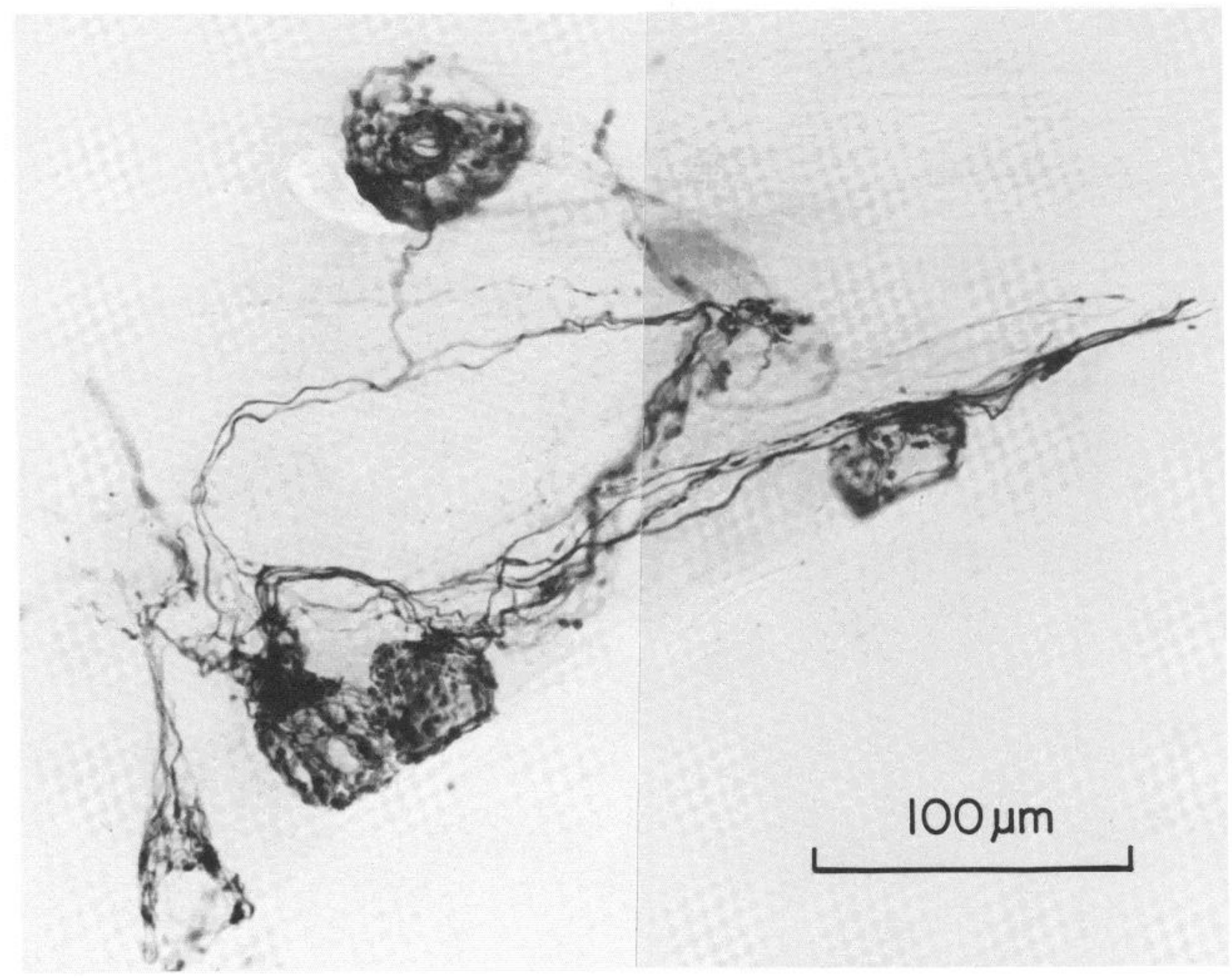


However, whether those cells were singly or multiply innervated was not known. The present results suggest that innervation by different axons on the somata of multiply innervated ganglion cells may be fairly common. First, the innervation of dendrites by labeled axons was usually associated with synaptic boutons on the relevant cell body. This observation suggests that most ganglion cell somata receive some innervation from each of the several axons which innervate their dendrites. Second, ganglion cell somata (as dendrites) often received only a small number of synaptic boutons from a labeled axon. Such minimal contacts on the cell body (as on a dendrite) presumably coexist with innervation by other inputs. Indeed, it is clear from electrophysiological studies of cells which lack dendrites altogether that minor innervation from a second or third input is sometimes present (Purves and Hume, 1981; see also Lichtman, 1977, 1980). Whether the cell bodies of neurons with dendrites are more hospitable to innervation by several different axons than cell bodies lacking dendrites remains unclear. However, the overall ability of preganglionic axons to elaborate boutons on ganglion cell somata is apparently reduced in the presence of multiple inputs, since the density of boutons on the cell bodies of neurons with two or more dendrites is only about half that on singly innervated, adendritic ciliary ganglion cells (Hume and Purves, 1983),

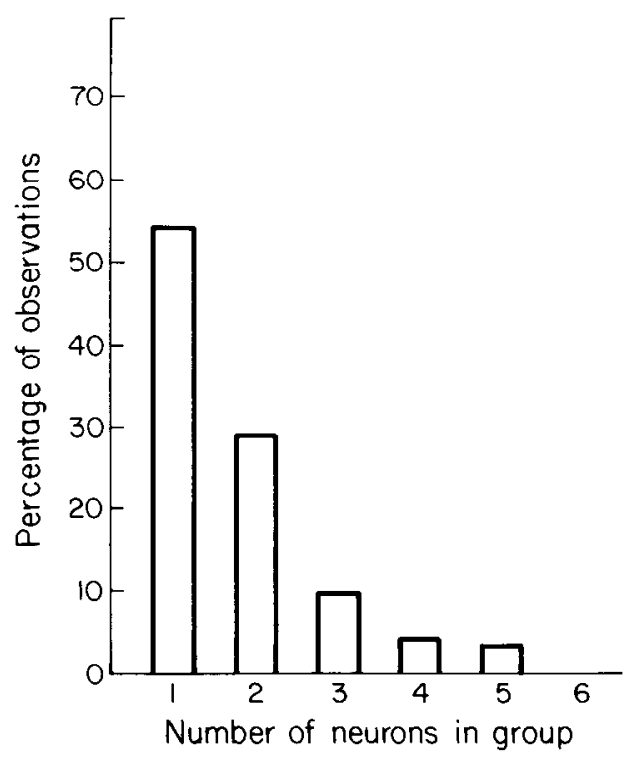

Figure 8. Histogram showing the frequency of ganglion cell body innervation in isolation, pairs, triplets, and so on (cf. Fig. 7). Although the majority of target cells are innervated in isolation, clusters of two to five contiguous cell bodies innervated by a labeled axon were often observed $(n=432)$.

\section{Conclusion}

The work described here extends a series of studies on the way in which the number of inputs innervating target neurons is controlled. Our results suggest that the ultimate correlation between postsynaptic neuronal geometry and number of inputs to rabbit ciliary ganglion cells arises because the terminals of different axons achieve a degree of segregation on a neuron with dendrites. This partial segregation may allow multiple inputs to be maintained during the normal period of synaptic rearrangement in early postnatal life.

The winnowing of inputs to target cells that occurs during development in a number of systems is thought to involve competition among the axons which initially innervate target cells (Purves and Lichtman, 1980; Purves, 1983). Accordingly, to increase the final number of inputs to a target cell competition must in some way be mitigated. The regional separation of inputs made possible by neuronal dendrites may be one way of achieving this effect.

\section{References}

Blackstad, T. W. (1967) Cortical grey matter-A correlation of light and electron microscopic data. In The Neuron, $\mathrm{H}$. Hyden, ed., pp. 49-118, Elsevier-North Holland Publishing Co., Amsterdam.

Fox, C. A., and J. W. Barnard (1957) A quantitative study of the Purkinje cell dendritic branchlets and their relationship to afferent fibres. J. Anat. 91: 299-313.

Hamlyn, C. H. (1963) An electron microscopic study of pyramidal neurons in the Ammon's horn of the rabbit. J. Anat. 97: 189-201.

Hanker, J. S., P. E. Yates, C. B. Metz, and A. Rustioni (1977) A new specific, sensitive and non-carcinogenic reagent for the demonstration of horseradish peroxidase. Histochem. J. 9: 789-792.

Hume, R. I., and D. Purves (1981) Geometry of neonatal neurones and the regulation of synapse elimination. Nature 293: 469-471.

Hume, R. I., and D. Purves (1983) Apportionment of the terminals from single preganglionic axons to target neurones in the rabbit ciliary ganglion. J. Physiol. (Lond.) 338: 259275.

Johnson, D. A., and D. Purves (1981) Post-natal reduction of neural unit size in the rabbit ciliary ganglion. J. Physiol. (Lond.) 318: 143-159.

Johnson, D. A., and D. Purves (1983) Tonic and reflex activity recorded in ciliary ganglion cells of anaesthetized rabbits. $J$. Physiol. (Lond.) 339: 599-613.

Lichtman, J. W. (1977). The reorganization of synaptic connexions in the rat submandibular ganglion during post-natal development. J. Physiol. (Lond.) 273: 155-177.

Lichtman, J. W. (1980) On the single innervation of submandibular ganglion cells in the rat. J. Physiol. (Lond.) 302: 121130 .

Figure 7. Example of the distribution of terminals from an HRP-labeled preganglionic axon (photomontage of a 50 - $\mu$ m section). The axon was labeled intracellularly near the junction of the ganglion with the oculomotor nerve, which is out of the field to the right. Several presumptive ganglion cell somata are invested to varying degrees by synaptic boutons and preterminals. Some of the cells are isolated whereas others are adjacent; the isolated cells would be counted as singles in Figure 8 , and the two contiguous cells would be counted as a pair. In addition, numerous processes apparently unrelated to ganglion cell bodies are evident, some with few or no boutons along their length. The processes lacking boutons represent preterminal branches (see Fig. 4 , for example); processes with boutons are presumably associated with ganglion cell dendrites. Note that the cell body on the bottom left appears to have been cut at the section surface; such a cell would not have been counted in the determinations of boutons on cell bodies. The line which runs diagonally across the photograph represents the lateral margin of the ganglion; the picture includes about $50 \%$ of the area of the ganglion in horizontal section. 
Lichtman, J. W., and D. Purves (1980) The elimination of redundant preganglionic innervation to hamster sympathetic ganglion cells in early postnatal life. J. Physiol (Lond.) 301: 213-228.

McMahan, U. J., and S. W. Kuffler (1971) Visual identification of synaptic boutons on living ganglion cells and of varicosities in the postganglionic axons in the heart of the frog. Proc. $R$. Soc. Lond. Biol. 177: 485-508.
Purves, D. (1983) Modulation of neuronal competition by postsynaptic geometry in autonomic ganglia. Trends Neurosci. 6: 10-16.

Purves, D., and R. I. Hume (1981) The relation of postsynaptic geometry to the number of presynaptic axons that innervate autonomic ganglion cells. J. Neurosci. 1: 441-452.

Purves, D., and J. W. Lichtman (1980) Elimination of synapses in the developing nervous system. Science 210: 153-157. 